\title{
The relationships of Bisphenol A levels with leptin and adiponectin in premenopausal women
}

Sevgi Polat, Banu Şarer Yürekli, Gökçen Ünal Kocabaş, Raika Durusoy, Murat Akşit, Giray Bozkaya, Arif Yüksel , Füsun Saygilı

Ege University Faculty of Medicine, Endocrinology Department

\section{Objectives:}

Bisphenol A (BPA) is the most common endocrine disruptor among environmental estrogens. BPA is an ingredient that is commonly used in polycarbonate plastics. In this study; our main concern is to measure the levels of BPA in premenopausal obese women and to examine the relationship of BPA with adiponectin and leptin.

\section{Methods:}

47 obese women and 39 non-obese healthy women were enrolled in this study. All participants were premenopausal. In this crosssectional study, all participant's BPA, adiponectin and leptin levels were measured. BPA levels in serum were measured by ELISA method. Obese and control group mean values were compared by $\mathrm{t}$ test. BPA's relationship with other parameters were analyzed by Spearman rank correlation. The average values were presented with the standard deviation.
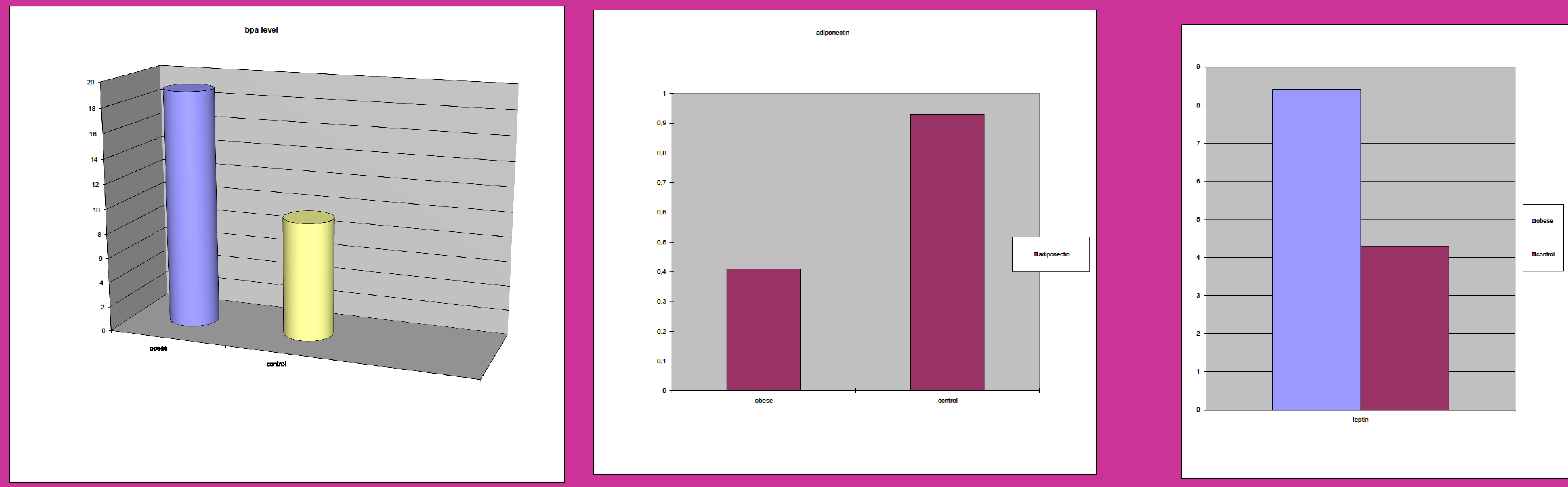

\section{Results:}

The average age of obese premenopausal women were 34.4 and 33.4 in the control group $(p=0.56)$. BMI mean value of the obese participants was $34.1 \pm 4.0 \mathrm{~kg} / \mathrm{m} 2$ and the control group's mean BMl value was $22.8 \pm 1.6 \mathrm{~kg} / \mathrm{m} 2(p$ $<0.001)$. BPA levels in obese women were significantly higher than the control group $(1.19 \pm 8.12 \mathrm{ng} / \mathrm{ml}$, in obese and $9.5 \pm 1.13 \mathrm{ng} / \mathrm{ml}$ in the control group , $p=0.001$ ). All groups in the analysis; there were a significant positive correlation between leptin and BPA levels $(r=0.317, p=0.003)$, and a negative correlation between BPA levels and adiponectin $(r=-0.269, p=0.012)$.

\section{Conclusions:}

There are many recent studies showing the relationship between BPA and obesity. The effects of BPA that impair the regulation of body weight and lead to obesity may be related to the disruptive effects on adipocyte differentiation, fat deposition, insulin resistance and impact on the secretion of adiponectin. 